\title{
The Development of Risk Management System in Primary Schools
}

\author{
Charoen Srisaenpang ${ }^{1}$, Chaiyuth Sirisuthi ${ }^{1} \&$ Subunn Ieamvijarn ${ }^{2}$ \\ ${ }^{1}$ Faculty of Education, Mahasarakham University, Thailand \\ ${ }^{2}$ Faculty of Mahasarakham Business School, Mahasarakham University, Thailand \\ Correspondence: Charoen Srisaenpang, Faculty of Education, Mahasarakham University, Mahasarakham \\ Province 44000, Thailand. E-mail: charoen52@gmail.com
}

Received: September 19, 2013 Accepted: October 15, 2013 Online Published: December 31, 2013

doi:10.5539/ass.v10n1p43 URL: http://dx.doi.org/10.5539/ass.v10n1p43

\begin{abstract}
This research aimed to; study the risk management and its process, develop the appropriate risk management system, and figure out the system implemented outcomes in Primary Schools in Northern Part of Thailand. The study was Research and Development (R\&D) in nature. The study designed into three phases; investigating the current situations and problems of risk management was designed in the first phase.The risk system development and its implementation were designed the second and third phase. The research tools comprised of focused group discussion forms, semi-structure interview forms, and assessment forms. Percentage, Means, and Standard Deviation (SD) were used as statistic analysis tools. The results showed that; there are four aspects of risks management were employed to view the risk in primary school included strategic, operational, financial, and compliance aspects. Five steps of risk management process included; communication and awareness, identification, risk analysis and assessment, planning and management, and monitoring and evaluation of the risk were found. Based on the Multi-Attributed Consensus Reading (MACR), showed that the developed risk system management was appropriated to apply in primary schools. The implementation outcomes which feedbacks by the implementers showed high performance of staffs, high standard of operational risk management, high quality of works, and high rank of satisfaction by the implementers.
\end{abstract}

Keywords: system development, risk management, primary school, Thailand

\section{Introduction}

The dynamic situation of the world was intensive, violent, and continuous as in the present. As a result, every organization including the public sectors or private sectors has to improve and change as well as select to use the appropriate instruments for developing the organization, and has to be congruent with one's own organization to be used in development and assessment in order to live as well as progress sustainably, and be able to compete with the same kind of organization. (Ieamvijarn, 2004: 4) The Act of Bureaucratic Management Rule of the Ministry of Education 2003, Section 20, al Education Act specified the Ministry of Education, the Office of Bureaucratic Development Commission (BDC) specified the indicator of success in establishing risk management system for official sectors by managing the factors, and controlling the activities as well as various implementation processes in order to decrease the causes of each opportunity that causes the threat in organization into level as well as amount of potential risk which might be occurred in the future, into level which could be accepted, evaluated, controlled, and checked systematically by considering the goal accomplishment of organization based on strategies. (The Office of Bureaucratic System Development, 2005: 65-67)

Therefore, it was indispensable for the schools to study and comprehend the usage of risk management system in Primary School, so that the implementation of schools would accomplish the specified goal.

\section{Literature Review}

The National Education Act 1999, Section 4, Paragraph 5, stated that "Basic education institutions" means those providing basic education. In addition, on Section 4, Paragraph 6, it is stated that "Educational standards" means specifications of educational characteristics, quality desired, and proficiency required of all educational institutions. They serve as means for equivalency for purposes of enhancement and monitoring, checking, evaluation, and quality assurance in the field of education. Moreover, in Section 6, it is stated that Education shall aim at the full development of the Thai people in all aspects: physical and mental health; intellect; knowledge; morality; integrity; and desirable way of life so as to be able to live in harmony with other people. 
Chaiyuth Sirisuthi (2002: 4-5) defined "System" as the working process helping to improve one's work efficiency to accomplish goal, including Input, Process, and Output. Kowat Tedsabutr (2011: 13-21) defined "System" as the different factors combining into one (factor set) related in one direction to accomplish desired goal, and the changes in one part would affect the another one as well. Wayne K. Hoy and Cecil G. Miskel (2008: 20-21) stated that the opened system was a system relating to structure and process. It was a system of change for security and flexibility. The organization was also an opened system with implementation based on role and function, as unstable relationship for survival of organization which had to adjust oneself throughout the time. It had to depend on each other as well as environment by giving an importance of usefulness facilitating to each other as the regulation and commitment among the nearby organizations.

Edwards (1985: 20) stated that the cycle in system development consisted of (1) Systems Analysis, (2) Systems Design, and (3) Systems Development. Stair (1996: 411-412) proposed System Development Life Cycle (SDLC) including 5 steps as follows: (1) Systems Investigation, (2) Systems Analysis, (3) Systems Design, (4) Systems Implementation, and (5) Systems Maintenance and Review. Effy Oz (2009) stated the principle of system development consisted of the planning, the analysis, the design, the usage, and the support.

Ton Soontarayoot (2007: 152) defined the Risk as any situation or action which might occur in unstable situation, and might affect or cause damage or failure or decrease the opportunity to accomplish goal as well as objective in national level, organizational level, or work unit. Pricewaterhousecoopers (2547: 4) defined the Enterprise Risk Management as a process performed by committee of company, administrator, and everyone in organization to specify strategy as well as implementation by the risk management process which was designed to indicate potential incidence and impact on organization, and be able to manage the risk in level to be accepted by organization in order to be reasonably confident in accomplishing the specified objective of organization. Robert R. Moeller (201: 31-45) classified the risk in business organization including: the strategic risk, the work practice risk, the financial risk, and the implementation risk and technology risk. Anna Dimitriadi and Sophia Dimitriadi (2007: 20) stated the process of risk management as the control in occurred and potential risk including the following processes: (1) The specification and comprehension in risk, (2) The evaluation of potential impact, (3) The expectation in related persons who were affected, and (4) The implementation of risk management.

\section{Research Methodology}

Research and Development was administered in this study. The research methodology could be classified into 3 phases as follows:

Phase 1: The risk situation and risk management process in Primary School was studied.

Phase 2: The appropriate risk management process in Primary School was developed.

Phase 3: The effect of application in risk management process in Primary School was studied.

\section{Research Methodology}

Phase 1: The study of risk situation, and risk management process in Primary School. The population in this study were Primary School under jurisdiction of the Office of Primary Educational Service Area in North Eastern Region, and 62 Educational Service Areas. Office of Primary Educational Service Area was classified into 3 groups including: 1) the North Eastern Region, 2) the Middle North Eastern Region, and 3) the lower North Eastern Region. The samples for Focus Group Discussion were 3 Educational Service Areas. There were total of 27 key informants.

Phase 2: The development of appropriate risk management process in Primary School was the step of conclusions in various factors of system by using the information from the study in phase 1 and from field trip study at 3 Primary School with quality risk management system as the guidelines for outlining the system, and being considered its appropriateness as well as possibility if tentative system by experts. The factors of appropriate risk management process in Primary School included: 1) the Input Factors of risk management process in Primary School: Strategic Risk -S Operational Risk - O Financial Risk - F and Compliance Risk - C 2 ) the process of risk management system, 3) the product of risk management system in Primary School, and 4) the Feedback of system.

Phase 3: The effect in using the risk management system in Primary School was studied by using the risk management system in 2 Primary Schools, and the schools were selected by Purposive Sampling. This study was an Action Research using the principles: 1) the development of awareness and readiness including plan for work practice, 2) the usage of risk management in Primary Schools by the researcher and Primary School Administrators. The usage of risk management in Primary Schools was implemented for 3 months by providing 
workshop in implementing based on handbook of risk management in Primary Schools, and 3) the Investigation and following up the implementation, and the evaluation in usage of risk management system in Primary Schools.

\section{The Findings}

The study of risk situation as well as risk management processes in Primary Schools, by using Focus Group Discussion with Primary School Directors in 3 Educational service Areas, found that the Primary Schools consisted of 4 risk situations such as: 1) the strategy including the administration system management and organizational development, the development of Internal Quality and Educational standard System, 2) the action aspect including the school curriculum development, the instructional management in school, and Educational Supervision, 3) the Financial aspect including the establishment of financial report, the investigation as well as following up and reporting the budget spending, and the collection of resources as well as investment for Education, and 4) the implementation of the rule, law, and principle including management activity for the students' behavior modification. Risk management processes consisted of 5 steps including: the communication and comprehension in organizational goal, the exploration and specification of risk, the analysis and assessment of risk, and the following up and investigation of risk.

The development of appropriate risk management in Primary Schools consisted of 4 major factors as: the strategic factor with 2 sub-factors, the action factor with 4 sub-factors, and the financial factor with 3 sub-factors. The major factors implementation is followed by rule, law, and principle included 1 sub-factor. For the risk management process system, it consisted of 5 major steps. The system output including the staffs' quality, the standard of risk management as well as quality of work performance, feedback of system including the assessment of risk management report, usefulness, and satisfaction of users in risk management system.

The findings of usage in risk management system of Primary Schools, according to the assessment by Risk Management Committee of schools, were as follows: 1) staffs' average value of quality was in the "Highest" level, 2) the implementation based on standard of risk management was in the "Highest" level, 3) the quality of work performance was in "the Highest" level, 4) the evaluation of findings in risk management was in the "Highest" level, 5) the evaluation of usefulness of risk management system was in the "Highest" level, and 6) the satisfaction of users in risk management system was in the "Highest" level.

\section{Discussions}

According to the study, there was interesting information to be discussed as follows:

\subsection{Situation of Risk Management and Risk Management Process in Primary}

Schools according to Focus Group Discussion with Primary School Directors were found that there were 4 aspects of risk situations as: the Strategic aspect, the Action aspect, the Financial aspect, the implementation followed by rule, law, and principle which were the risks could occur since the administrators and teachers didn't have knowledge and comprehension in usage of risk management system in schools, and it is necessary to have the risk management system for helping the implementation to accomplish organizational goal. It was supported by Torben Juul Andersen and Peter Winther Schroder (2010: 127-128) who classified the types of risk into the strategic risk, the implementation risk, the environmental condition and financial aspects. In addition, they also specified that the strategic risk was the most important in organization. It was congruent with Robert R. Moeller (2011: 31-45) who classified the risk in business organization into 4 aspects as: the strategic risk, the work practice risk, the financial risk, and the information communication and technology risk. For risk management process, it consisted of 5 steps as: the communication and comprehension in organizational goal, the exploration and specification of risk, the analysis and synthesis of risk, the planning and risk management, and the following up as well as checking of the risk. It was support by Ton Soontarayoot's (2007: 174-180) statement of guidelines for risk management in organization including: the exploration of risk, the searching and specifying the risk, the analysis of risk, the assessment and ranking of the risk, the management of risk, and the investigation of risk. It was congruent with Suranaree Technology University's (2011: 1-8) statement of risk management process in Suranaree Technology University including 10 steps of process as: the management of structure in risk management of university, the determination of practice framework, the specification of risk factors as well as opportunity value of risk and impact, the assessment of risk, the determination of acceptable risk level as well as appropriate technique for risk management, the establishment of risk management planning, the following up and evaluation of risk management plan, the establishment of report in risk management of fiscal year, and asking for approval from University Council. It was congruent with Malcolm Taylor's (2000: 13-17) statement that the risk management was an activity implementing the specification of danger or opportunity of loss which caused by threatening or impact from work practice as well as careless work practice, determining the weight as 
well as significance of impact in every activity of organization, ranking order of risk, specifying the risk which could be reduced as well as couldn't be reduced, developing the strategy for controlling as well as reducing that risk, and the management based on specified strategy. It was congruent with Carl L. Pritchard's (2001: 5-9) classification in 6 risk management steps including: the planning for risk management, the specification of risk, the situation of risk, the amount of risk, the response to risk, and the investigation and controlling of risk. It was supported by Terje Aven's (2003: 1-4) statement of present implementation of organization or work units, the first thing to be considered was the competency in risk management including in every factor of work. The kinds of risk had to be classified for being information in decision making fort preparation as well as finding the measure of risk management for the most benefit of organization. It was congruent with Ruth Taplin's (2005: 7-10) article in "An interdisciplinary and cross-cultural approach" of Ruth Taplin and Nick Schymyck regarding to guidelines for risk management as responsibility of every one in organization, including the following implementation steps: the determination of risk, the assessment of risk, the control of risk, and the risk management. Furthermore, in risk management, it was required to assess the congruence with organizational strategy, and checked by experts in risk management to be ascertained. It was supported by Torben Juul Andersen and Peter Winther Schroder' (2010: 128-132) statement of strategic risk management process which the strategy could be adjusted throughout the time in order to be relevant to real situation obtaining from revision, following up, and evaluation. It was congruent with Marijana Trivunovic, Jesper Johnson and Harald Mathisen' (2011: 6-8) statement regarding to risk management of corruption in Non-governmental organizations : NGOs including the widespread use of risk management process as the specification of risk or threatening on project objective, the assessment of severity of risk, the specification and ranking the significance of measure for reducing those risks, the usage of measure for alleviating opportunity as well as impact from the risk. It was supported by Robert R. Moeller's (2011: 31-45) basic principle in risk management including the specification of risk, indicator of risk assessment, the analysis of quantitative risk: the expectancy value and planning to serve the situation.

\subsection{The Appropriate Risk Management System in Primary Schools}

The Appropriate Risk Management System in Primary Schools Obtained from the field trip study at 3 Primary Schools with Best Practice, by interviewing the administrators as well as work practitioners, observation, and documentary study from all of 3 schools in order to design the system, and presenting tentative system to the experts to be investigated its appropriateness as well as possibility to practice by using MACR Focus Group Discussion, concluded that the risk management system was appropriate in every aspect including the system planning, the system design, and the usage. The risk management in Primary School consisted of 4 major factors: the strategic factor included 3 sub-factors as the organizational management system, the organizational development, and the development of Internal Quality Assurance and Educational Standard; the action factor included 4 sub-factors as the curriculum development of school, the instructional management in schools, the Educational supervision, and the assessment of work performance; the financial factor included 3 sub-factors as the establishment of financial and financial budget report, the investigation, following up, and report of budget spending, and the collection of resources as well as investment for Education; and the major factor of practice following rule, law, and principle included 1 sub-factor as the activity management for students' behavior modification in punishment. The system process consisted of 5 major steps including (1) the communication and comprehension in organizational goal, (2) the exploration and specification of risk, (3) the analysis and assessment of risk, (4) the planning and management of risk, (5) and the following up as well as investigate the risk. The system output included the staffs' quality. The schools implementation is based on standard of risk management as well as quality of work performance and feedback including the report of risk management, the usefulness, and satisfaction of users in risk management system. It was congruent with Kanidta Chairfattanawan's (2011: 1) study in the Development of risk management process in instructional management of Department in Private Higher Education Institutions ISO 31000, it was found that the ISO 31000 was an appropriate administration and management with Thai Education System including 5 major steps as: 1) communication and consultation, 2) the establishment of context, 3) the risk assessment, 4) the treatment or management of the risks, and 5) the monitoring and reviewing. The major objective of ISO 31000 included development and improvement of standard which would enhance the organizational development by allowing every staff in organization to participate in searching for weak point, strong point, opportunity, and threat of organization, determining the organizational strategy as well as monitoring and reviewing the implementation. It was congruent with Duangchai Cheuytrakool's (2008: 316-318) study in risk management in Basic Education Schools, it consisted of 5 factors as: the learning and teaching, the finance, the Educational Confidence, the environment, and the security administration and management. There were significant differences in risk factors between the schools in urban, rural, and in each Region at .05 level. The guidelines of risk management, the 
controlling as well as searching for measure in preventing the risk were in aligned with transferring of risk by collaboration of students, parents, school staffs, community, school board, and related persons. It was supported by Poom Pechsakdadech and Suwimol Wongwanich' (2011: 14-27) study in the assessment of Lower Secondary School Students' risk for being dropped out, found that there were 12 risk factors classifying the dropped out students from the other groups of students as follows: 1) 4 family factors including the parents/caretakers' income, father's Educational Level, Father's occupation, and Mother's occupation, 2) 2 risk factors of teacher/school as the teachers didn't provide home visit, and there were no teachers to listen to the problems as well as advice the students, 3) 2 risk factors of students as the late school attendance, and absenteeism, 4) 4 risk factors of friends as the friend used to have 0 , incomplete work, late attendance, the inattentive friends, the dropped out students, and friends who preferred to use violence. It was congruent with Preecha Chantawee's (2010: 259-263) development of Assessment System and Educational Risk Control for School: An Assessment of Empowerment, found that there were 6 factors of Assessment System and Educational Risk Control of Primary Schools as: (1) the study of environmental situation and task analysis of school, (2) the assessment of risk, (3) the control of risk, (4) the communication and opinion sharing, (5) the monitoring and assessment, and (6) the report of findings. It was supported by Kasetsat University Demonstration School's (2011: 97-99) implementation in risk management system including the appointment of risk management committee, the analysis and specification of risk, the establishment of risk management planning and implementation, monitoring as well as evaluating the implementation according to plan, and reporting to the school management committee at least once a year, and reporting to the school management committee, using the findings of assessment as well as suggestions from school management committee for modifying the plan or analyzing the risk in next annual year by the conference in implementation findings as well as informing the conference of school management committee. It was supported by The International Organization for Standardization (2009: $\mathrm{v}$-vii) that the risk management process consisted of the application of management policy system, the steps and practice methods in communication management activity, the consultation, the determination of environmental situation, the specification, the analysis, the evaluation, the management, the investigation and revision of risk. It was congruent with Autorité des marchés financiers' (2010: 5-6) statement of factors in risk management system including the organization's work frame, the process of risk management in organization, and the external environment of organization as well as continuous monitoring and revision. It was supported by Torben Juul Andersen and Peter Winther Schrøder' (2010: 128-132) statement of factors in risk management including the specification of risk, the analysis of risk, the assessment of risk and responding to risk, the efficient internal environment or organization, the leadership, the organizational culture, the organizational management. It was congruent with Robert R. Moeller' s (2011: 21-29) statement of risk management including the assessment of risk and planning, the specification of risk and analysis, the utilization, and the development of strategy for responding to the risk, and the monitoring and checking the risk. It was supported by Constanta Iacob and Stefan Zaharia' (2012: 1-9) study in Risk Management, found that the factors of risk management including the contextual study, the assessment of risk, the management of risk, and the monitoring, reviewing, and reporting. It was congruent with Adrian Solomon Panayiotis Ketikidis and Alok Choudhary' (2012: 1-5) study in the Supply Chain Risk Management: SCRM by knowledge-based so that the Supply Chain Risk would be flexible, with automatic and up to date decision making, found that there were 11 factors relating to risk management including: the fluency, the shared information usage, the trustworthiness, the collaborated relationship, the maintenance of information security, the responsibility for society and organization, the creation of motivation and policy of portion from revenue, the strategic planning of risk, the sharing of risk, the knowledge of risk, and the continuous analysis of risk.

\subsection{The Findings of Using Risk Management System in Primary School}

For the staffs' quality, it is found that both of school administrators and teachers gave an importance to the usage of risk management system in schools, the committees of risk management in schools were appointed. They were aware of delimitation, duty, responsibility in work practice clearly. They had knowledge and comprehended in risk management system of schools. The committees of risk management participated in risk management of schools. In addition, the schools implemented based on risk management system continuously.

The schools' implementation, based on standard of risk management, included: the establishment of quality handbook of risk management, the appointment of committee in risk management of schools, the determination of criterion for scoring the opportunity of risk, the criterion of scoring the impact value, criterion of level of risk in work or activity, the exploration and determination of risk, the analysis and assessment of risk, the plan for risk management, the practice following the specified risk management plan, the monitoring, evaluation, reporting the findings of risk management, and the usage of findings from risk management and suggestions 
from committees of risk management in planning for development in next academic year.

The quality of work performance was found in "the Highest" level since the administrators and teachers had knowledge and comprehension in the usage of risk management system in schools by implementing standard of risk management. It was congruent with the Advanced Info Company limited (Public) (2011: 123) that stated the advantage of risk management is an important mechanism to accomplish goal and success as well as to increase of value for stakeholders. It was supported by Autorité des marchés financiers' (2010: 5-6) statement of risk management in helping the correct and safe decision making, implementing to achieve organizational goal, creating confidence in value of work implementation of organization. It was also congruent with The International Organization for Standardization's (2009: v-vii) statement in usefulness from efficient risk management as the prevention and creation of additional value.

The feedback of usage in risk management system in 2 schools was found as of the following:

1) The assessment of report in risk management in both schools found that the school risk management was in "the Highest" level. This findings indicated that the administrators and teachers obtained knowledge and comprehension in risk management system in schools. The committees of risk management knew the delimitation of their duty as well as responsibility in school risk management. There was an implementation based on the handbook of system usage. The document reporting the findings of risk management was congruent with real situation of schools. Moreover, the risk of schools was decreased into acceptable level.

2) Both schools obtained the findings of assessment in usefulness of risk management system in schools in the "Highest" level. Considering on the implementation with quickness, correctness, being standardized, decreased loss, being worthwhile, the system was appropriate with school context. The usefulness was obtained by schools. Consequently, the schools could elevate their competitive level, and serve the stakeholders' needs.

3) The satisfaction of users in risk management system was found in the "Highest" level since the administrators and teachers had knowledge and comprehended in the risk management with the availability of risk management handbooks in Primary Schools. Furthermore, they understood how to implement based on school responsibility in order to accomplish the vision, mission, and objective of schools. When the risk management system based on its risk management handbooks was used, the schools could improve their competency in competition as well as serve the stakeholders' needs.

\section{Conclusions}

From the findings of this study, the risk management system was obtained to be used in Primary Schools. It was appropriate with current situation as well as practical, and useful for school management in order to achieve goal based on major responsibility of schools.

\section{Recommendations}

\subsection{Recommendations for Applying the Research Findings}

- In order to use the risk management system in Primary School with the administrators and teachers; the documents, system, and risk management handbook in Primary Schools should be studied for obtaining knowledge as well as comprehension and awareness, and seeing the importance as well as advantage should be studied.

- The implementation based on handbook of usage in risk management system in Primary Schools should be performed.

- For system usage, the appropriateness based on school context should be considered.

- The risk management system would be efficient when committee of risk management knew their role and duty, and participated in risk management.

- The public relation regarding to guidelines for risk management in schools should be performed in order to develop understanding with students and their parents.

- The risk management in schools should be continuous and up to date.

- The supervision as well as following up the implementation based on the risk management in school should be performed.

- For better efficiency of risk management, the school staffs should be promoted to develop their knowledge and comprehension by attending the conference as well as training in "risk management in organization."

- The risk management system should be used as organizational culture. 
- The staffs' motivation should be created in order to improve the efficiency in implementation by using the risk management system so that the work would be quick in term of the controlling, and the creation of responsibility towards schools.

- The committee of risk management should have opportunity for field trip studying in the successful risk management work units.

- The committee from the Office of Educational Service Area should assess the risk management in schools at the end of school year.

- The evaluative findings in usage of risk management in schools should be reviewed as the guidelines for improving framework of risk management, policy, and work plan in next year.

- The schools under the Office of Educational Service Area should hold conference for sharing their learning and experience, success, and obstacle in using the risk management system in schools.

\subsection{Recommendations for Future Research}

- The research study of development in risk management system should be conducted especially in the development of students' learning achievement or behavior.

- The comparative study of usage in risk management system in schools with different sizes or contexts should be conducted.

- The risk management by using new technique and method in risk analysis, risk assessment, and prediction for potential risk which would occur in future should be conducted.

- The study for integration of connection among the schools with successful private organization in risk management should be conducted.

- The study of risk management in small sized Primary School should be conducted by the experts in risk management from both of public sector, and private sector to join in the committee of risk management in school as case study, should be conducted.

\section{References}

Advanced Info Service Co. Ltd. (Mass). (2011). The Annual Report 2011. Bangkok: Advanced Info Service Co. Ltd (Public).

Andersen, T. J., \& Schrøder, P. W. (2010). Strategic Risk Management Practice: How to Deal Effectively with Major Corporate Exposures. New York: Cambridge University Press. http://dx.doi.org/10.1017/CBO9780511816017

Aven, T. (2003). Foundations of Risk Analysis: A Knowledge and Decision-Oriented Perspective. West Sussex: John Wiley \& Sons Ltd. http://dx.doi.org/10.1002/0470871245

Chairattanawan, K. (2011, May-August). Universal Risk Management ISO 3100 and Thai Educational System. Veridian E-Journal SU., 4(1), 419-434.

Chantawee, P. (2010). Development of Assessment and Controlling System of Educational Risk for School: An Assessment as Empowerment. Doctor of Philosophy Thesis. Mahasarakam: Mahasarakam University.

Chuaytrakool, D. (2008). Risk Management in Basic Education School. Doctoral Dissertation. Bangkok: Silpakorn University.

Dimitriadi, A., \& Dimitriadi, S. (2007). A Conceptual model of Risk Management and its importance for Sport \& Leisure. Sport Management International Journal, 3(1), 20.

Edwards, P. (1985). Systems Analysis, Design and Development: With Structured Concepts. New York: Holt, Rinehart and Winston.

Hoy, W. K., \& Miskel, C. G. (2008). Educational Administration: Theory, Research, and Practice (8th ed.). New York: McGraw-Hill.

Iacob, C., \& Zaharia, S. (2012). Risk Management-A New Piority System Customs and ITS Consequences. Romania: University of Craiova.

Ieamvijarn, S. (2004, August-October). Balance Scorecard (BSC): The Instrument for Progressive Management of Thai Higher Education Institutions. Journal of Graduate Study: Sakon Nakhon Graduate Studies Journal, $1(4)$.

Kasetsat University Demonstration School. (2011). Self Assessment Report in 2010 Academic Year. Bangkok: 
Kasetsat University Demonstration School.

Moeller, R. R. (2011). COSO enterprise risk management: Establishing effective governance, risk, and compliance processes (2nd ed.). New Jersey: John Wiley \& Sons, Inc. http://dx.doi.org/10.1002/9781118269145

Office of Bureaucratic System Development Commission. (2005). Risk Management (2nd ed.). Bangkok: The Cabinet and Government Gazette.

Oz, E. (2009). Management Information Systems (6th ed.). Massachusetts: Course Technology.

Pechsakdasiri, P., \& Wongwanich, S. (2011). The Risk of Lower Secondary School Students' Dropping Out. Academic Journal, 14(3), 14-27.

Pricewaterhousecoopers. (n. d.). Guidelines for Risk Management. Pricewaterhousecoopers International Limited.

Pritchard, C. L. (2001). Risk Management: Concepts and Guidance. ESI International: Virginia.

Sirisoot, C. (2012). System Development. Mahasarakam: Mahasarakam University.

Solomon, A., Ketikidis, P., \& Choudhary, A. (2012). A Knowledge Based Approach for Handling Supply Chain Risk Management. The University of Sheffield. Retrieved from http://seerc.org/refbase/files/solomon/2012/695_Solomon2012.pdf

Soontarayoot, T. (2007). Educational Risk Management. Bangkok: Netikool Printing Ltd.

Stair, R. M. (1996). Principles of Information Management System: A Managerial Approach (2nd ed.). Boston, M.A.: Course Technology.

Suranaree Technology University. (2011). The Handbook for Risk Management of Suranaree Technology University. Nakonrachasima: Suranaree Technology University.

Taplin, R. (2005). Risk Management and Innovation in Japan, Britain and the United States. New York: Routledge.

Taylor, M. (2000). Avoiding Claims in Building Design: Risk Management in Practice. London: Blackwell Science Ltd. http://dx.doi.org/10.1002/9780470690413

Tedsaboot, K. (2011). The Handbook for Educational Management in 0511902 the Application of System Theory in Educational Administration and Development. Mahasarakam: Mahasarakam University.

The Government Gazette. (1999, August 19). National Education Act 1999, 116 ${ }^{\text {th }}$ Issue, 74 a Part, pp.1-13.

The International Organization for Standardization. (2009). Risk Management-Principles and Guidelines. Geneva: ISO copyright office.

Trivunovic, M., Johnsøn, J., \& Mathisen, H. (2011). Developing an NGO corruption risk management system: Considerations for donors. U4 Anti-Corruption Resource Centre: Bergen.

\section{Copyrights}

Copyright for this article is retained by the author(s), with first publication rights granted to the journal.

This is an open-access article distributed under the terms and conditions of the Creative Commons Attribution license (http://creativecommons.org/licenses/by/3.0/). 